\title{
Factors Contributing to Seasonal Fluctuations in Rust Severity on Ribes missouriense Caused by Cronartium ribicola
}

\author{
Maria Newcomb, Christen D. Upper, and Douglas I. Rouse
}

Department of Plant Pathology, 1630 Linden Dr., University of Wisconsin-Madison, Madison 53706.

Current address of M. Newcomb: Small Grains and Potato Germplasm Research Unit, U.S. Department of Agriculture-Agricultural Research Service, 1691 S. 2700 W., Aberdeen, ID 83210.

Current address of C. D. Upper: 8454 Highway 19, Cross Plains, WI 53528.

Accepted for publication 21 May 2010.

\begin{abstract}
Newcomb, M., Upper, C. D., and Rouse, D. I. 2010. Factors contributing to seasonal fluctuations in rust severity on Ribes missouriense caused by Cronartium ribicola. Phytopathology 100:986-996.

Cronartium ribicola, causal agent of white pine blister rust, is a macrocyclic heteroecious rust that cycles between white pines and members of the genus Ribes, which are typically wild plants in North America. To improve predictability of inoculum available for infection of ecologically and commercially important white pines, this research was conducted to identify the factors that influence the development and persistence of uredinia and telia on Ribes in their natural habitats.

lating rust sori) on tagged Ribes missouriense plants in the woods fluctuated during the season. Changes in numbers of infectious rust lesions were related to rain that occurred 13 days earlier. In field experiments, supplemental leaf wetness provided for 2 days on Ribes shoots resulted in the development of rust lesions more frequently than on control shoots. Viable inoculum and susceptible hosts were present, and the environment was the limiting factor for disease development. Lesion necrosis and leaf abscission contributed to decreases in numbers of infectious rust lesions. Higher lesion density was significantly related to earlier leaf abscission. Telial fruiting bodies occurred in low numbers from early June throughout the remainder of the season.
\end{abstract} Numbers of infectious $C$. ribicola rust lesions (with potentially sporu-
Many pathogens that impact commercially important host plants are also pathogens of wild plants during parts of their life cycles $(6,30,39,43)$. Typically, research attention is directed at the interaction between the pathogen and its commercial hosts, regardless of the importance of the wild hosts in the life cycle of the pathogen. Diseases of wild plants are gaining increasing research attention in their own right for their diverse influences on natural plant communities $(2,7)$. However, there are surprisingly few quantitative epidemiological studies of economically important pathogens that focus on parts of the pathogen's life cycle that extend beyond the commercial hosts. This knowledge gap is especially notable for heteroecious rust pathogens, which require alternate host groups to complete their life cycles. In the case of Cronartium ribicola, the cause of white pine blister rust, the aecial white pine hosts are valued for commercial and ecological reasons while North American currants and gooseberry hosts in the genus Ribes are most commonly wild plants that are not valued. The aecial hosts can only be infected by basidiospores that are produced while the rust pathogen is on its Ribes host. Nevertheless, the epidemiology of the disease on Ribes remains poorly understood.

When host plants are grown in high-density monocultures with vigorous growth favored by practices such as fertilization, weed and pest control, and irrigation, rust epidemics that occur are characterized by a rapid, monotonic increase to a carrying capacity limit. The logistic model for disease progress, based strictly on density dependence, was popularized in agricultural plant pathology in writings by van der Plank in 1963 and later

Corresponding author: M. Newcomb;

E-mail address: Maria.Newcomb@ars.usda.gov

doi:10.1094/PHYTO-12-09-0349

(C) 2010 The American Phytopathological Society (reviewed in 42). Despite increasing study of rust populations in noncommercial systems $(1,5,24,28,38)$, we still lack knowledge of whether simple models for disease increase are relevant for rust populations on wild hosts where hosts and environments may be much more variable. This is a critical knowledge gap for heteroecious rusts when the inoculum that can infect commercially valued hosts is produced while the pathogen is on wild hosts.

White pine blister rust is a severe threat to white pine hosts, and ecosystems which support white pines, in many parts of the United States and Canada $(14,16)$. It is also one of the most important causes of timber loss in North America (15). Cronartium ribicola was introduced to North America approximately a century ago $(9,18)$. The rust alternates between white pine and Ribes hosts to complete its life cycle. Two fruiting structure stages occur while the rust is a foliar pathogen on Ribes. The uredinial stage produces urediniospores which can reinfect Ribes, but cannot infect white pines. The telial stage produces teliospores which germinate in place to produce basidiospores. The basidiospores cannot reinfect Ribes, but are the only spores that can infect the pine hosts. Pine infection occurs when basidiospores germinate and infect needles. The resulting mycelium grows to the stem where it persists perennially and induces canker development. Canker expansion results in eventual girdling of the tree or branch, which can result in mortality (20). To improve predictability of inoculum available for infection of ecologically and commercially important white pines, we must first understand the factors that influence the abundance and timing of uredinia and telia on Ribes.

Ribes are woody perennial shrubs. There are approximately 50 species of Ribes native to North America (19), where most of the Ribes that host $C$. ribicola are native, noncultivated plants. On the Ribes hosts, the rust is a foliar pathogen and does not enter the woody stem. Aeciospores are wind-dispersed from white pine to Ribes hosts. Given appropriate leaf moisture conditions, penetra- 
tion of Ribes leaves can occur through stomata on lower leaf surfaces. Uredinia develop on the underside of leaves and release urediniospores 10 to 30 days after infection. Telial columns are also produced by the rust on the underside of Ribes leaves, often following and replacing uredinial production (20). An important difference between the life cycle of $C$. ribicola and many other well-known rusts is that the telial stage is not a resting or overwintering stage. Telia of $C$. ribicola remain viable on living, attached, host leaves. Viability decreases on dead or detached leaves $(35,36)$, and in all probability is insufficient to allow overwinter survival.

This study primarily focused on $R$. missouriense, with supporting data collected on $R$. cynosbati, a closely related species, and $R$. hudsonianum, a black currant that is readily propagated. $R$. missouriense is a woody, perennial shrub with stout spines and edible berries that is native to the Midwest. It grows in mesic to dry, open woodlands, thickets, fence-rows, and rocky slopes from New Jersey west to North Dakota, and from Ontario south to Arkansas and Tennessee. $R$. cynosbati is a closely related species (19) that grows in similar habitats over a broader north-south distribution in eastern North America. Stems of both species can be erect to sprawling, with multiple stems growing from a single root crown. New stem development occurs on terminal and lateral shoots of current year's growth (40). R. missouriense can be an important component of the woodland understory in southern Wisconsin, where it has increased in abundance between surveys conducted in the late 1940s and 2004 (26).

The overall goal of our research was to develop an understanding of the epidemiology of $C$. ribicola on wild Ribes in their natural habitat. Initial observations led us to the conclusion that the amount of disease on Ribes at any given time during the season was highly variable. We sought explanations for sources of this variability as a means to understand the important forces that direct these annual epidemics.

The literature provides some observational data with regard to the disease on Ribes (20), but provided little guidance for quantitative understanding of the processes driving annual epidemics. Controlled-environment studies have shown that urediniospore germination on host leaves requires the presence of free water, and begins after 4 to $6 \mathrm{~h}$ of wetness with higher germination rates occurring after $12 \mathrm{~h}$ (41). In field environments, rust disease on some species of Ribes has been reported to be associated with premature leaf abscission $(13,35)$. While anecdotal descriptions of the presence of uredinia and telia of C. ribicola on Ribes exist, and include speculations about the influence of factors such as rainfall and host defoliation, few quantitative data are available describing temporal trends in field conditions. Even the seasonal timing of telial production is not clear. Telia have been reported throughout the summer and early fall in British Columbia (10), but to our knowledge a quantitative seasonal description of telial presence and abundance is not available for any region. Given the lack of available data, one of the top research needs identified for white pine blister rust is to gain a better understanding of the part of the pathogen's life cycle that occurs on Ribes hosts (31).

This research was conducted to identify factors that contribute to the seasonal dynamics of $C$. ribicola on a wild gooseberry host. We monitored rust on Ribes hosts in their natural habitats throughout two growing seasons. In order to identify important factors influencing rust severity, we conducted manipulative experiments both in the natural field environments and in a cold frame.

\section{MATERIALS AND METHODS}

Study sites. The research was conducted in upland, deciduous woodland sites in Dane County, Wisconsin. Most of the experiments were conducted on privately owned land located on the north side of Highway 19, within $1.3 \mathrm{~km}$ of Indian Lake County
Park (Fig. 1). Within these lands, $R$. missouriense occurred at high densities in woodlots with different management histories. Some woodlots had been lightly harvested as recently as 2004 and other woodlots not since 1969. The diverse management history allowed for selection of reasonably independent sites that were proximally located to increase the probability of exposure to common weather and inoculum. Additionally, the overall high density of $R$. missouriense allowed sufficient sample sizes of plants to be located within a reasonably small area to increase the likelihood of exposure to common conditions within a site. While plants typically occurred in an irregular distribution, some were separated by less than a meter and some by several or more meters.

The main experiments aimed at quantifying season-long patterns in disease severity were conducted at four sites designated as East, West, North, and South sites in Figure 1. The East site was selected because of its close proximity to Eastern white pine (Pinus strobus L.) Christmas tree plantings. The white pines provided a source of aeciospore inoculum. The East and West sites were monitored over two seasons (2007-2008). The North and South sites were monitored during the second season only (2008). An additional study site, referred to as the Blackhawk site, was used for a different experiment that involved a comparison between $R$. missouriense and $R$. cynosbati, a closely related species that can overlap in range and habitat with $R$. missouriense. The Blackhawk site was located in Dane County approximately $8.7 \mathrm{~km}$ to the northwest of the main study sites shown in Figure 1 on property managed by the Wisconsin Department of Natural Resources. The Blackhawk site was also an upland, deciduous

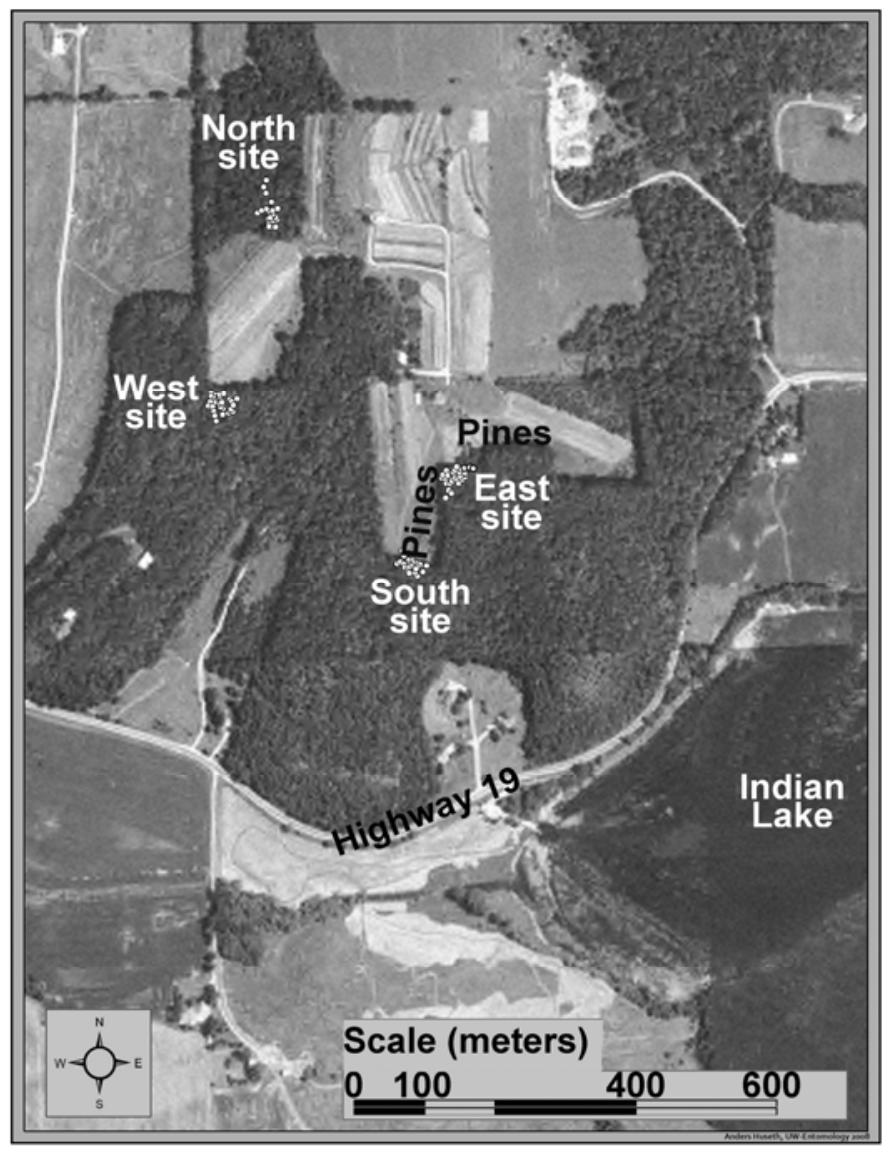

Fig. 1. Aerial view of the woodland sites used in the study. Darker areas show deciduous woodlands and conifer plantings that include white pine hosts for Christmas tree sales (two areas labeled Pines on the map). Clustered points mark locations of plants of Ribes missouriense (as determined by GPS) that were monitored for Cronartium ribicola during both study years (East and West sites), or the second year only (North and South sites). 
woodland habitat that had been managed by light and selective harvesting practices. Pole-size white pines in a mixed conifer plantation were present immediately to the south of the research site.

Whole-plant rust monitoring. Healthy, mature plants that were separated by at least $2 \mathrm{~m}$ were tagged for monitoring in early April (30 and 31 plants at the West and East sites, respectively, in 2007, and 24 at each of the North and South sites in 2008). Plants were selected and tagged prior to full leaf development, and thus prior to rust infection. Woodland plants were frequently multistemmed with up to nine stems growing from one root crown (mean 3.2 stems and SE 0.19 stems for the 61 plants selected in 2007). All stems were tagged for plants with one to three stems. When there were more than three stems within a plant, three stems were randomly selected and tagged for monitoring.

Rust severity was rated on all tagged stems from late April to middle to late October in the 2007 and 2008 seasons by the same person. Ratings were typically conducted every 5 days, although the timing occasionally varied between every 3 to 8 days in 2007 . Ratings were regularly conducted at 5-day intervals in 2008.

In this paper, we define rust severity by numbers of lesions that had living fruiting bodies (uredinia, telia, or both). This is because of our interest in the potential for disease spread to new hosts, and because the rust pathogen only persists and is infectious while colonizing attached and living host leaves. Lesions with living fruiting bodies were distinguished by the orange-red color of the uredinia and/or telia. Living fruiting bodies were potentially sporulating and thus potentially infectious. When the rust fruiting bodies became completely necrotic, which occurred in association with necrotic leaf tissue, these necrotic lesions were not included in severity measures $(23,34)$. On each monitoring date, numbers of infectious rust lesions were recorded for all leaves with at least one infectious lesion on all the tagged stems. Leaves without rust were not enumerated. Telia were noted as present or absent on each tagged stem.

Host defoliation was also rated on tagged plants on each monitoring date. Defoliation severity was estimated for each tagged stem using a categorical rating $(0=$ none; $1=$ minor $[<5 \%] ; 1.5=$ minor/moderate $[6$ to $10 \%] ; 2=$ moderate $[11$ to $30 \%$ ]; $2.5=$ moderate/heavy [30 to $40 \%$ ]; $3=$ heavy [40 to $75 \%$ ]; $3.5=$ heavy/mostly $[76$ to $90 \%] ; 4=\operatorname{mostly}[>90 \%]$; and $5=$ total). While these categorical defoliation ratings at the level of plant stems were rough approximations that captured overall site trends, more accurate data on timing of leaf abscission was possible on tagged shoots where leaves were monitored individually for rust and timing of abscission (see below).

Leaf-level rust monitoring. To better identify and understand processes contributing to seasonal fluctuations in rust severity, leaves were identified by their position on lateral shoots for a subset of the tagged plants described above. Selected shoots were mostly located on separate plants. Shoots from separate plants were treated as experimental units. When two shoots were located on the same plant, the shoots within a plant were considered subsamples and measurements from these subsamples were averaged. Identified leaves were assessed individually over time in order to record rust severity, timing and abundance of telial development, and timing of leaf abscission. This allowed for investigations of the relationship between rust severity and timing of leaf abscission, as well as infectious periods per leaf. In this paper, we define infectious period for leaf units as the number of days for which potentially sporulating fruiting bodies were present on each leaf. To control for some of the variability in leaf size, leaf density, and exposure to light, leaves on shoots of the current year's growth were selected after new shoot development was complete at the end of May. In 2007, there were 16 and 17 tagged shoots at the East and West sites providing 156 and 132 leaves, respectively. For each leaf on tagged shoots, numbers of infec- tious lesions, numbers of lesions with telia and whether the leaf remained attached or not, were recorded on every monitoring date. A similar protocol for tagging and monitoring individual leaves was followed at all four main sites in 2008.

Leaves on tagged shoots of the current year's growth were also monitored on plants of $R$. missouriense and $R$. cynobasti at the Blackhawk site. At this site, 96 leaves on 14 plants of $R$. missouriense and 122 leaves on 16 plants of $R$. cynosbati were monitored over the 2007 season. The same data variables were recorded for the leaves on tagged shoots at the Blackhawk site as at the main sites, except that higher rates of lesion coalescence on $R$. cynosbati were accounted for by estimating percent leaf area with infectious rust lesions instead of counting numbers of lesions on this species.

Effect of rainfall and environmental factors. To evaluate environmental factors for potential relationships with rust severity, on-site daily rainfall measurements were recorded, and additional environmental variables (air temperature, relative humidity, vapor deficit, and solar radiation) were recorded at the nearest weather station in Arlington, Wisconsin in 2007. Rainfall totals were recorded at 6 am daily to the nearest hundredth inch $(0.25 \mathrm{~mm})$ with a rain gauge located in a large clearing approximately $100 \mathrm{~m}$ to the north of the East site. Relationships between rust severity (numbers of infectious rust lesions) and environmental variables were explored by summarizing daily meteorological variables between rust observation dates in multiple ways (by calculating averages, sums, and maximum and minimum values). Relationships were tested with and without various delays (lag times). Because daily rainfall was the only variable that revealed a detectable relationship with rust severity in 2007, it was the only variable that was rigorously followed in 2008.

Effect of leaf wetness in the field. To determine if the relationship between rain and increased numbers of infectious lesions was due solely to the occurrence of leaf wetness, a misting and bagging experiment was conducted in 2008 in areas adjacent to the East site. Disease-free leaves were misted with deionized water just before sunset and enclosed in plastic bags for 44 to $48 \mathrm{~h}$. In each of four trials, conducted on 3, 5, 21, and 22 July, 39 to 48 rust-free shoots of the current year's growth were misted and bagged. Each rust-free shoot was located on a separate plant, and was treated as an independent experimental unit. An equal number of control shoots were tagged and left to the ambient environment. Fifteen days later, the number of newly developed rust lesions was recorded for leaves on misted and control shoots.

Effect of rust severity on leaf abscission. Two experiments using potted $R$. hudsonianum plants in a cold frame were conducted to compare the timing of leaf abscission among three rust severity treatments. The treatments were established by inoculating leaves with different concentrations of spore suspensions. Both experiments followed a randomized complete block design with each treatment randomly assigned to individual leaves within a block (plant stem). There were two trials conducted during each of two experiments. The three rust severity treatments were initiated by inoculating with spore suspensions at concentrations of $600,1.2 \times 10^{4}$, and $2.5 \times 10^{5}$ spores $/ \mathrm{ml}$. The second experiment included those three treatments and an uninoculated control as well. There were 26 (trial 1) and 25 (trial 2) stems (or blocks, with each treatment present in every block for 26 and 25 replicates of each treatment) in the first experiment and 24 stems (providing 24 replicates of each treatment) in each of the two trials in the second. Different strains of C. ribicola were used to prepare the urediniospore suspensions used in the two experiments. During the first experiment, the suspension was prepared using a single-spore isolate originally derived from aeciospores collected from a diseased white pine in Menominee County, Wisconsin. In the second experiment, the suspension was mixed using a spore strain originally collected from a single canker on a 
white pine tree growing adjacent to the woodland sites where Ribes monitoring occurred during this study.

After inoculation, plants were incubated in dew chambers $\left(18^{\circ} \mathrm{C}\right.$ in the dark) for $48 \mathrm{~h}$ and then moved to cold frames exposed to outdoor conditions. Every 2 to 4 days until all leaves had abscised, ocular estimates were made of the percent leaf area colonized by uredinial and telial fruiting bodies for every leaf, and any abscised leaves were noted. Ocular estimates were categorical $($ low $=0$ to $10 \%$, medium $=10$ to $60 \%$, and high $=$ greater than $60 \%$ leaf area with rust) in experiment 1 , and to the nearest percent leaf area with rust in experiment 2 . To quantitatively describe the rust severity levels in the second experiment, photographs were taken 22 days postinoculation and rust severity was estimated by ASSESS image-analysis software (APS Press). These estimates of rust severity among treatment groups were made before any symptoms appeared from a second generation of infection.

Data analyses. The relationship between daily rainfall and rust severity per plant (the total number of infectious lesions on tagged plants/number of plants per site) on each observation date for each site-year was investigated. To relate amounts of daily rainfall with counts of infectious rust lesions that were typically recorded every 5 days, different methods of summarizing the rainfall data between rust observations were explored. Methods that were tested included calculation of the maximum, sum, and mean of daily values, as well as frequencies of days above various threshold rains. Additionally, different lag times (from 10 to 20 days) on the rainfall data were tested, and relationships with rust severity were assessed with and without an exponential filter to smooth the data trend. An exponential filter (sometimes referred to as simple exponential smoothing) is a common method in timeseries modeling that utilizes an updating formula involving the most recent observation and the previous update (3). When relating an environmental variable that can change rapidly (i.e., daily rainfall) to a biological or physical variable that may respond less rapidly (i.e., rust severity), it may be appropriate to smooth the data trend slightly.

To determine the procedure for summarizing daily rainfall that provided the best fit with changes in rust severity, relationships between the lagged, smoothed rain values, and rust severity were assessed visually in temporal and scatter plots and then by correlation and regression analyses. Based on results from these exploratory assessments, we selected the following procedure: daily rainfall was lagged by 13 days, averaged between rust observations, and then smoothed. Average daily rainfall values (averaged between observation dates) were smoothed by applying an exponential filter, weighted by 0.9 (i.e., filtered rainfall for observation interval $t_{n+1}=[$ (previously filtered rainfall for observation interval $\left.\left.t_{n-1}\right) \times 0.1\right]+[($ unfiltered rainfall for observation interval $\left.\left.\left.t_{n}\right) \times 0.9\right]\right)$.

Categorical defoliation estimates for individual monitored stems were averaged within plants, allowing plant values to be the experimental units on which means and standard deviations were calculated. Defoliation trends were calculated separately by site and year.

The relationship between timing of leaf abscission and rust severity on field leaves was assessed over multiple observation dates. Numbers of infectious rust lesions on leaves that abscised before the next observation were compared with infectious lesions on leaves that remained attached during the same time interval. The frequency with which leaves that abscised had more rust than those that remained attached was compared using a binary sign test. Data on the timing of leaf abscission during the cold frame trials were compared among rust severity treatments with Fisher's exact test on two-by-three contingency tables (two rust severity treatments by three categories for timing of leaf abscission) with cell values representing the numbers of leaves in each treatment that abscised in each timing category. Separate comparisons were conducted between the low and medium severities and one between the medium and high severities.

All exploratory visual assessments were constructed in Excel or $\mathrm{R}$ (version 2.3.1) (25). Binomial sign tests, Fisher's tests, $t$ tests, and linear regressions were conducted in $\mathrm{R}(4)$. Linear regression model assumptions were considered through visual assessment of residual and normal score plots (plots not shown). To consider complications from autocorrelation, residuals were plotted against time, and Durbin Watson statistics were calculated (21). Autocorrelation was determined to not be a complication in all time series for all six site-years (plots and statistics not shown).

\section{RESULTS}

Seasonal trends in rust severity. Infectious rust lesions were recorded on 31 consecutive monitoring dates in both years. Lesions were first detected between 13 and 23 May for all siteyears. Numbers of infectious rust lesions per plant fluctuated substantially and displayed distinct peaks and troughs during both the 2007 and 2008 seasons (Fig. 2). Peaks in numbers of infectious rust lesions were generally preceded by major rain events (Fig. 2). To quantify the relationship between daily rainfall and numbers of infectious rust lesions, the best fit was between rainfall (lagged by 13 days, averaged and smoothed) and differences in numbers of infectious lesions per plant between two sequential observations. For five of six site-years, the changes in numbers of infectious lesions were significantly related to lagged, smoothed rainfall by linear models ( $P \leq 0.06, R^{2}$ between 0.09 and 0.20 , Fig. 3). Disease incidence and severity were low at the West site in 2008 (the largest increase in numbers of infectious rust lesions per plant between observations was five lesions for the entire season), and no significant linear regression was found for this site-year.

Effect of leaf wetness in the field. To determine whether leaf wetness alone was the cause of the association between rainfall and increases in numbers of infectious rust lesions, supplemental leaf wetness was provided by misting and bagging shoots of current year's growth. In all four trials of the experiment, leaves on shoots that were misted and bagged developed rust lesions more frequently than control shoots and leaves (Table 1), and the mean numbers of new lesions per leaf were greater for misted than control leaves (data not shown). When data were pooled across the four trials, the frequency of misted shoots that resulted in rust lesions was significantly greater than that of control shoots $(P=0.003$, Table 1$)$. Based on these results, a change in leaf wetness was all that was needed for infections to occur.

Lesion necrosis and leaf abscission. Numbers of infectious lesions tended to decrease during periods when no large rain events occurred (Figs. 2 and 3). Losses of lesions were due to either lesion necrosis or abscission of leaves that supported infectious lesions. In order to assess the relative importance of these two processes that defined the end of the infectious period, we followed the total number of infectious lesions on individual tagged leaves until they detached. Leaves that were observed with rust supported infectious uredinia and telia for 19 to 22 and 6 to 12 days, respectively, depending on site (Table 2). When a leaf with rust abscised, the infectious lesions present on the leaf at the date of the observation before abscission were considered to be removed due to leaf abscission. When a leaf with rust became noninfectious by lesion necrosis, the highest count of infectious lesions that had been observed for that leaf was attributed to removal by lesion necrosis. When averaged by plant, the mean numbers of lesions that were removed when a leaf became noninfectious by either leaf abscission or lesion necrosis were between 2.1 and 3.6 and between 1.6 and 3.2, respectively, depending on site (Table 2). Both leaf abscission and lesion necrosis were therefore quantitatively important mechanisms by which infectious lesions were removed from hosts. 
While the average time that individual leaves were colonized by infectious uredinia was approximately 19 or 22 days, and by infectious telia about 6 or 12 days (Table 2), infectious periods (defined as the number of days for which potentially sporulating fruiting bodies were present) per leaf varied considerably. Durations for infectious uredinia and telia on single leaves ranged from 2 to 110 days and from 2 to 80 days, respectively (Fig. 4). Durations of infectious fruiting bodies plotted against the maximum number of infectious lesions recorded per leaf provided no evidence for a negative correlation between infectious period and numbers of lesion (Fig. 4). This result suggests that in addition to disease-associated leaf abscission, other factors (i.e., frequency of rain events, host genetics, etc.) must affect the durations of infectious periods.

Effect of rust severity on leaf abscission. Throughout this study, it was observed that in shaded woodland habitats $R$. missouriense completed new shoot and leaf development by middle to late May. From middle June throughout the rest of the season leaves progressively abscised in a general pattern from the lower stem upward. The progressive seasonal defoliation changed the size and distribution of the infectable host area (Fig. 5). To determine if leaf abscission was influenced by rust severity during the growing season, the number of infectious rust lesions on leaves that abscised between pairs of observations was compared with that on leaves that remained attached during the same time period. During the 2007 season, rust severity was higher on leaves that had abscised before the next observation than on those that remained attached until the next observation for most observation dates (Fig. 6). In 2008, lower amounts of disease produced too few lesions on tagged leaves to provide useful data. We conducted a binary sign test on the data from 2007 with observation dates representing events, and a "successful" event representing the outcome with higher lesion density per leaf on leaves ready to
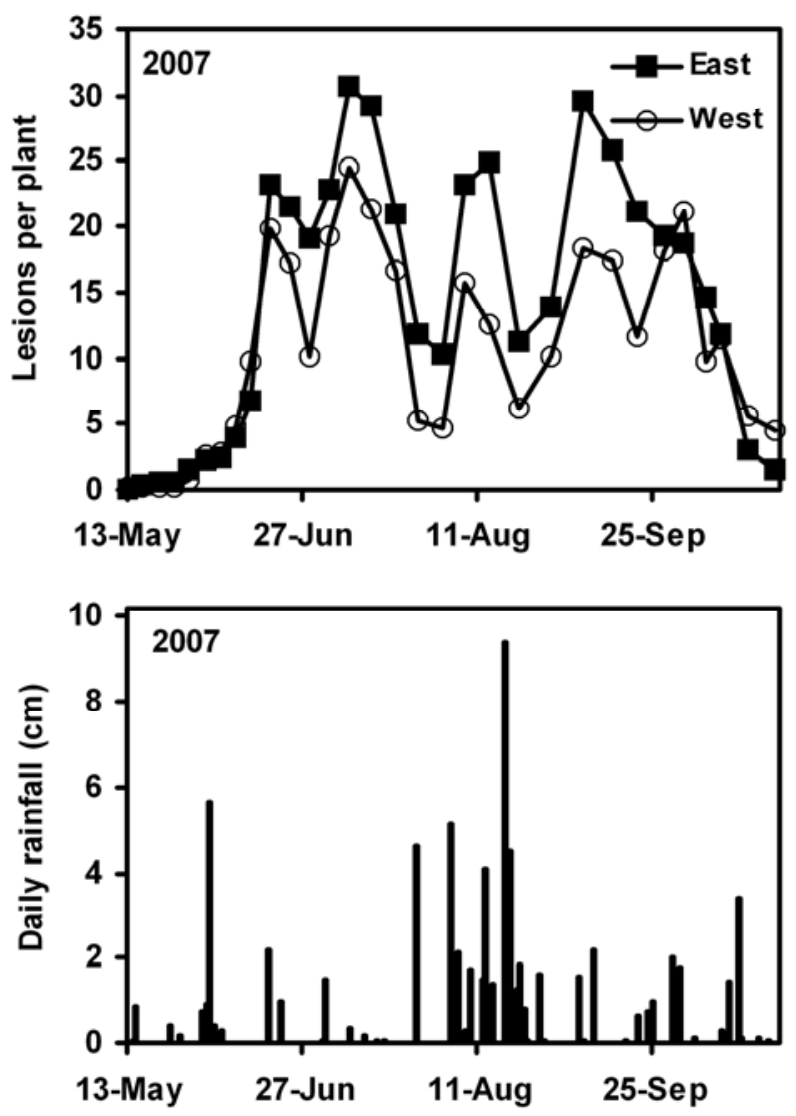

abscise (compared with leaves that remained attached). The empirical probabilities of a successful event for the East and West sites were 87 and $80 \%$, respectively (95\% confidence intervals of 60 to $97 \%$ and 52 to $96 \%$ ) and were significantly different from $50 \%(P=0.0074$ and 0.035$)$. The empirical probabilities of a successful event for plants of $R$. missouriense and $R$. cynosbati at the Blackhawk site were 77 and $83 \%$, respectively (95\% confidence intervals of 46 to $95 \%$ and 52 to $98 \%$ ), and were significantly different from $50 \%(P=0.092$ and 0.039$)$. Thus, higher lesion density was significantly related to earlier leaf abscission.

A leaf inoculation experiment was conducted on plants of $R$. hudsonianum to distinguish between the possibility that disease caused earlier abscission and the alternative possibility that leaves approaching abscission were more likely to become infected. Time between inoculation and leaf abscission was significantly decreased $(P<0.01)$ as rust severity was increased (Table 3$)$. Numbers of leaves within each rust severity treatment that abscised during three time intervals were significantly different when compared in two treatment by three time-interval contingency tables (eight total comparisons, with separate comparisons between low and medium severities and between medium and high severities, all with $P<0.01$ with multiple comparison corrections) (data shown pooled across trials in Table 3). The results suggest that rust severity on woodland plants $(R$. missouriense) was a likely cause of accelerated leaf abscission.

Seasonal occurrence of telia. If colonized leaves abscise before the rust has converted to telial production, the lesions that are removed have substantially less potential to produce basidiospores capable of infecting pine hosts. Given an intermittently favorable environment and an increased likelihood of leaf abscission for diseased leaves, the timing of telial development is important. In the 2007 season, telial columns were first detected on 10 June and were observed on every subsequent observation
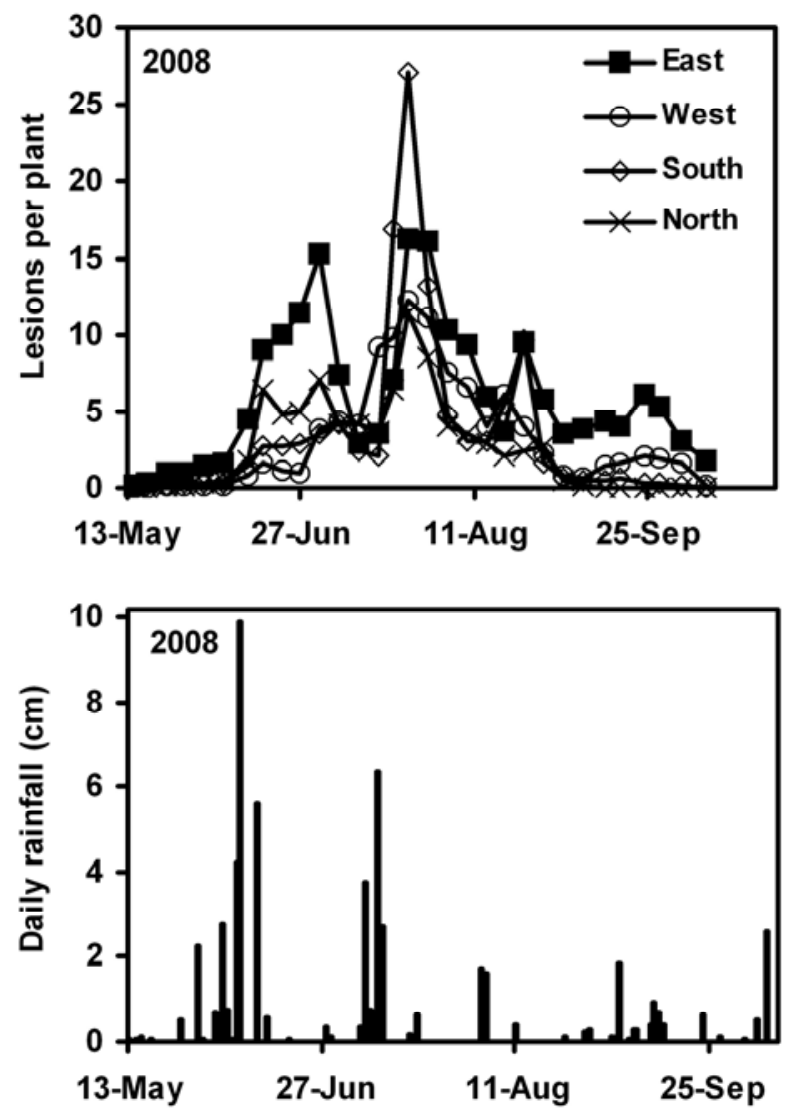

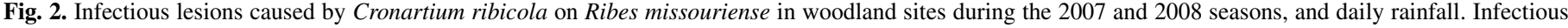

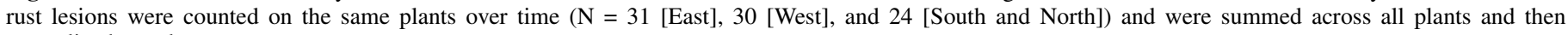
normalized per plant. 

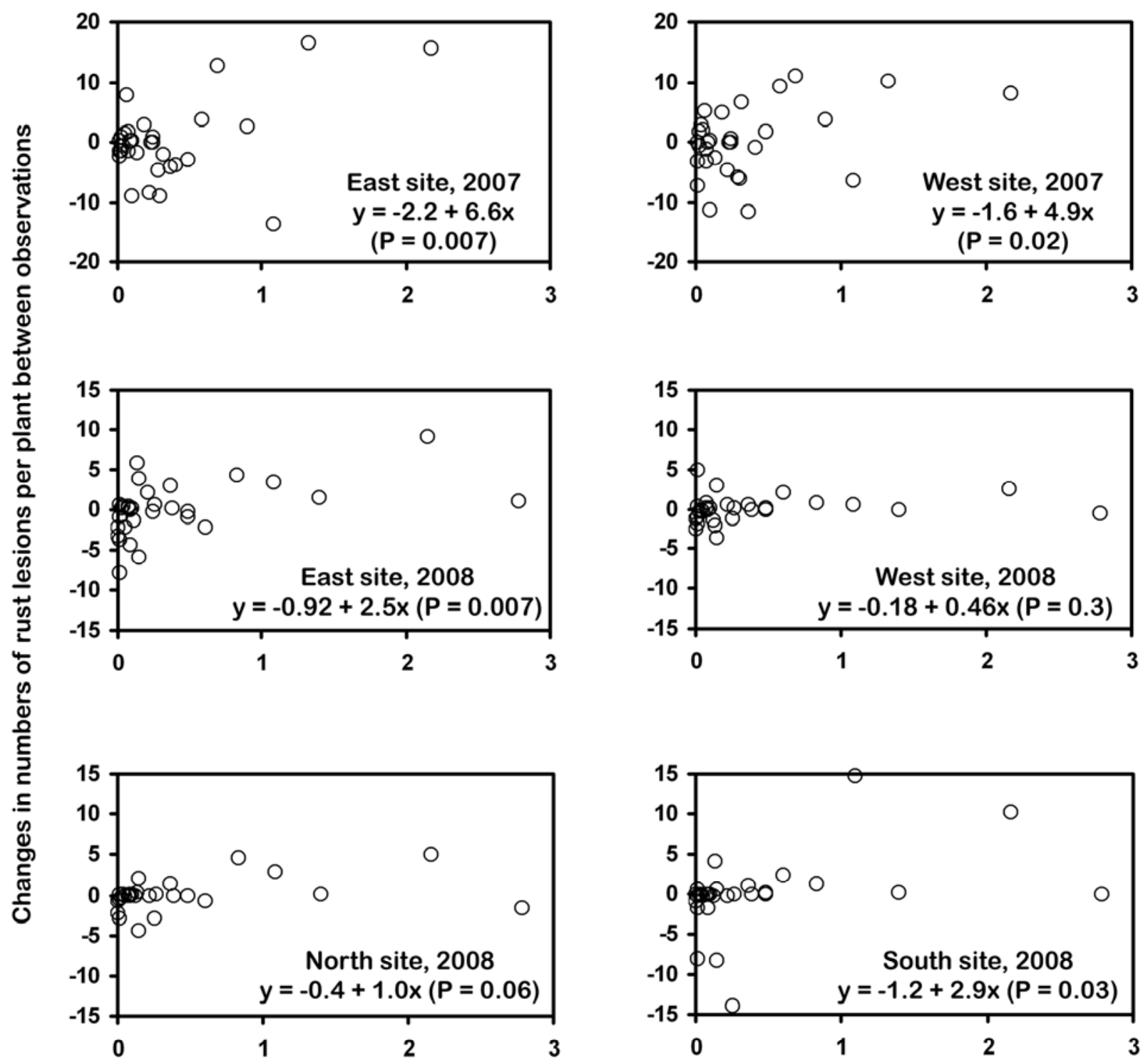

Daily rainfall $(\mathrm{cm})$, lagged by 13 days and averaged between rust observations

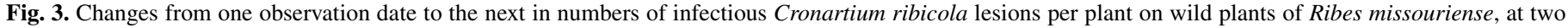

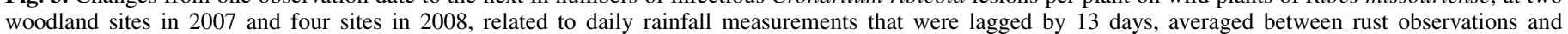

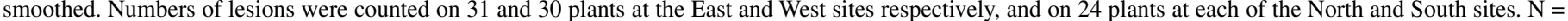
31 observation dates in both years at all sites. Linear regression equations are shown for each site/year with test results for the hypothesis that slopes are equal to zero.

TABLE 1. Development of lesions caused by Cronartium ribicola on plants of Ribes missouriense with and without supplemental leaf wetness in woodland sites ${ }^{\text {a }}$

\begin{tabular}{|c|c|c|c|c|c|c|c|c|c|}
\hline \multirow[b]{2}{*}{ Date of trial } & \multirow[b]{2}{*}{ Outcome $^{\text {b }}$} & \multicolumn{4}{|c|}{ Number of shoots (\%) } & \multicolumn{4}{|c|}{ Number of leaves (\%) } \\
\hline & & Bagged & Control & $\begin{array}{l}\text { Fisher's odds } \\
\text { ratio }^{c}(95 \% \mathrm{CI})\end{array}$ & $P^{\mathrm{d}}$ & Bagged & Control & $\begin{array}{l}\text { Fisher's odds } \\
\text { ratio }^{c}(95 \% \mathrm{CI})\end{array}$ & $P^{\mathrm{d}}$ \\
\hline July 3 & $\begin{array}{l}\text { Lesions developed } \\
\text { No lesions developed }\end{array}$ & $\begin{array}{r}5(10 \%) \\
43(90 \%)\end{array}$ & $\begin{array}{c}2(4 \%) \\
46(96 \%)\end{array}$ & $0.38(0.03,2.5)$ & 0.44 & $\begin{array}{c}9(3.3 \%) \\
265(96.7 \%)\end{array}$ & $\begin{array}{c}5(1.7 \%) \\
285(98.3 \%)\end{array}$ & $0.52(0.13,1.7)$ & 0.28 \\
\hline July 5 & $\begin{array}{l}\text { Lesions developed } \\
\text { No lesions developed }\end{array}$ & $\begin{array}{l}10(24 \%) \\
31(76 \%)\end{array}$ & $\begin{array}{c}3(7 \%) \\
38(93 \%)\end{array}$ & $0.25(0.04,1.1)$ & 0.067 & $\begin{array}{c}16(6.4 \%) \\
233(93.6 \%)\end{array}$ & $\begin{array}{c}5(2.0 \%) \\
239(98.0 \%)\end{array}$ & $0.31(0.09,0.89)$ & 0.024 \\
\hline July 21 & $\begin{array}{l}\text { Lesions developed } \\
\text { No lesions developed }\end{array}$ & $\begin{array}{r}7(17 \%) \\
35(83 \%)\end{array}$ & $\begin{array}{c}2(5 \%) \\
40(95 \%)\end{array}$ & $0.25(0.02,1.4)$ & 0.156 & $\begin{array}{c}13(5.6 \%) \\
219(94.4 \%)\end{array}$ & $\begin{array}{r}2(0.84 \%) \\
235(99.2 \%)\end{array}$ & $0.14(0.016,0.65)$ & 0.0034 \\
\hline July 22 & $\begin{array}{l}\text { Lesions developed } \\
\text { No lesions developed }\end{array}$ & $\begin{array}{r}6(15 \%) \\
33(85 \%)\end{array}$ & $\begin{array}{c}3(8 \%) \\
36(92 \%)\end{array}$ & $0.46(0.07,2.3)$ & 0.48 & $\begin{array}{c}12(5.4 \%) \\
209(94.6 \%)\end{array}$ & $\begin{array}{c}4(1.7 \%) \\
232(98.3 \%)\end{array}$ & $0.30(0.07,1.0)$ & 0.040 \\
\hline $\begin{array}{l}\text { Pooled across } \\
\text { dates }\end{array}$ & $\begin{array}{l}\text { Lesions developed } \\
\text { No lesions developed }\end{array}$ & $\begin{array}{r}28(16.5 \%) \\
142(83.5 \%)\end{array}$ & $\begin{array}{c}10(5.9 \%) \\
160(94 \%)\end{array}$ & $3.1(1.4,7.5)$ & 0.0030 & $\begin{array}{c}50(5.1 \%) \\
926(94.9 \%)\end{array}$ & $\begin{array}{c}16(1.6 \%) \\
991(98.4 \%)\end{array}$ & $0.30(0.16,0.54)$ & 0.000013 \\
\hline
\end{tabular}

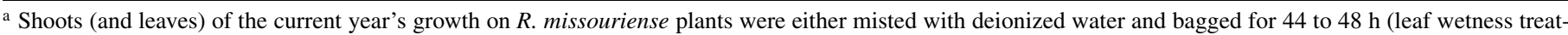
ment) or left to the ambient environment (control treatment). Only shoots with no evident rust colonization were selected for both treatment groups (although rust colonization was sometimes observed on other shoots within the same plants).

${ }^{b}$ All leaves on shoots of both treatment groups were examined for the presence of rust lesions 15 days after the leaf wetness treatment.

c Fisher's exact test results, odds ratio $=$ odds[event 1]/odds[event 2] such that an odds ratio $=1$ is evidence that the probabilities of events 1 and 2 are similar.

' Fisher's exact test result for the hypothesis that the odds ratio is equal to 1 . 
date through the end of the season. More colonized plants with telia than without were first observed on 29 June and 15 July 2007 at the East and West sites, respectively, and for most of the subsequent observation dates at both sites (Fig. 7). During 2008, telial columns were first detected on 28 May and were found on all subsequent observation dates. Beginning between 22 June and 7 July, depending on site, and for the remainder of the 2008 season, more plants were observed with telia than with only uredinia (Fig. 7).

By 21 September at the West site and 15 September at the East site, more infectious lesions on tagged leaves supported only telia (no uredinia) than only uredinia (no telia) during the 2007 season (Fig. 8). Telial columns were therefore present early in the season and for most of the season during both years, and dominated the fruiting body composition by middle September in 2007. Potentially, inoculum capable of infecting the pine host was present from late May, or early June, throughout the remainder of the growing season.

\section{DISCUSSION}

Knowledge of the factors that contribute to epidemics on Ribes is required to understand inoculum potential for white pine infection. Based on the collective evidence from this research, we present a partial working model for the dynamics of $C$. ribicola on $R$. missouriense. Increases in numbers of infectious rust lesions follow rainy periods by about 13 days but occasionally longer. Between rainy periods, the development of new rust

TABLE 2. Cumulative infectious periods for uredinia and telia of Cronartium ribicola on leaves of Ribes missouriense and numbers of infectious lesions removed when leaves became noninfectious either by lesion necrosis or leaf abscission

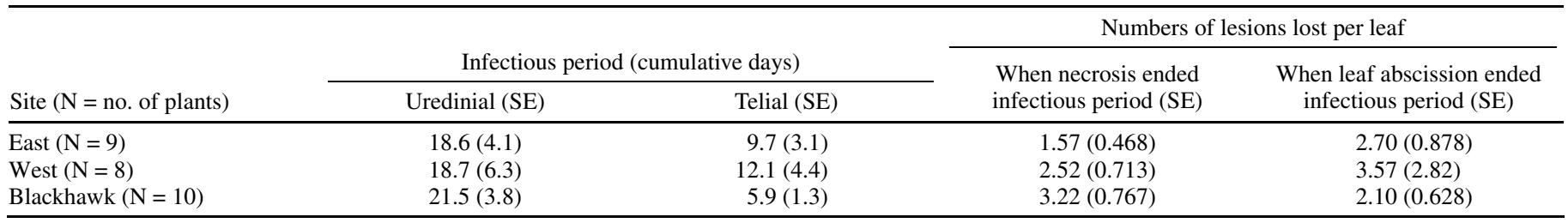
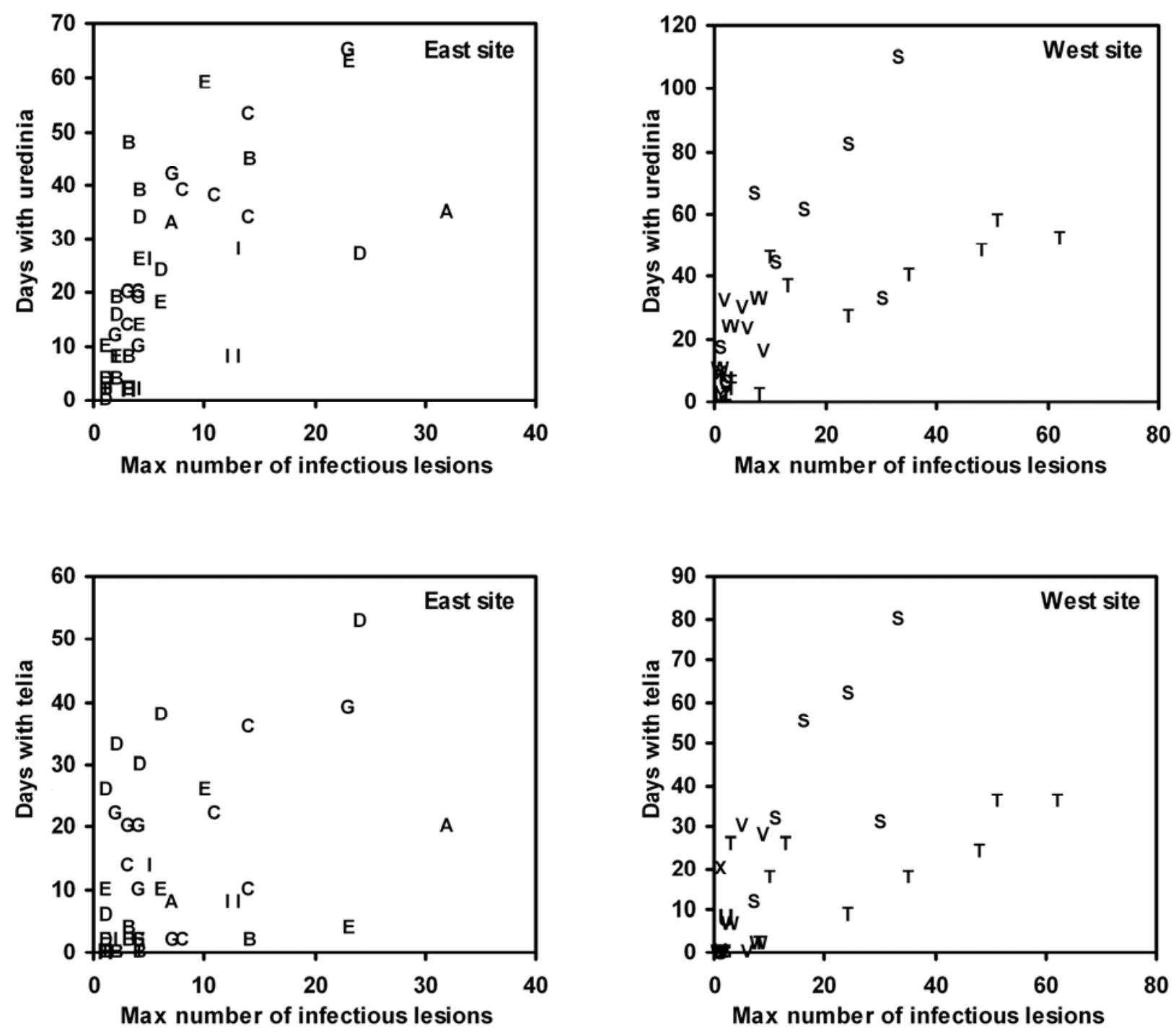

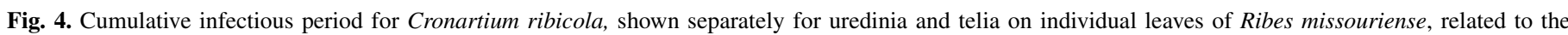
maximum number of infectious lesions recorded for each leaf. Leaves are coded by plant for nine and eight plants at the East and West sites, respectively, in 2007. 
lesions appears to be limited due to nonconducive environments rather than availability of inoculum. Losses of infectious lesions are due to both lesion necrosis and lesion-accelerated leaf abscission. Telia are present from early summer throughout the rest of the season, but peak telial production occurs in late September and October.

Rust and rainfall. Lagged, smoothed rainfall amounts greater than approximately $0.5 \mathrm{~cm}$ tended to be associated with increases in numbers of infectious rust lesions, while smaller rainfall amounts tended to relate to decreases in numbers of infectious rust lesions (Figs. 2 and 3, showing negative intercepts). The 13day lag time that generally provided the best fit with increases in numbers of rust lesions approximated the latent period (time from spore germination and infection to first fruiting structures). This interpretation is consistent with results of other experiments on $R$. missouriense in woodland habitats, such as the misting and bagging experiment conducted in this study, as well as inoculations of woodland Ribes conducted during a related study (M. Newcomb, C. D. Upper, and D. I. Rouse, unpublished data) in which most fruiting structures developed in approximately 14 or 15 days after inoculation. Some of the unexplained variation in numbers of infectious rust lesions may arise from approximating a frequency distribution of latent periods that is right-skewed with a single time of 13 days.

Although linear models with a 13-day lag significantly explained increases in infectious rust lesions following large rain events on most occasions, longer lags were required for a few other occasions. The peaks in lesion counts that occurred on 7 September 2007 and 2 July 2008 (Fig. 2) were better explained by lag times of 18 to 21 days for all sites (analyses not shown). On both of these occasions, infections were triggered by extended rainy periods that included heavy rains with more than $9 \mathrm{~cm}$ of rain in a single day. Whether, or how, these heavy rain events relate to longer lag times is not known. In general, residual analysis of the regression models suggests that additional factors influencing numbers of lesions remain unexplained.

Free water is necessary for spore germination and infection in this rust-host system (41). Although dew is an important source of leaf wetness in some rust-host systems (32), the significant relationship between rainfall and numbers of lesions caused by $C$. ribicola indicates that the intervening times between rainfall events were not associated with increases in rust. Since the times between rain events are when dewfall could occur, we interpret the lack of increase in rust as indirect evidence that dew was neither a sufficient source of leaf wetness to mask the significance of the single-factor relationship nor sufficient to maintain the rust pathogen on Ribes leaves. Beneath the woodland canopy, Ribes leaves apparently escaped dewfall which presumably fell on the leaves of the overstory canopy that were exposed to nighttime radiative cooling.

If the primary reason that lesion development follows rain events is that rain provides moisture necessary for infection to proceed, then artificially providing leaf moisture should similarly increase numbers of rust lesions. Indeed, leaves provided with free moisture for 44 to $48 \mathrm{~h}$, by misting and bagging, developed more new lesions than control leaves (Table 1). No inoculum was added during these experiments.

The average number of new lesions per leaf that resulted from artificial leaf wetness can be compared with an approximate number of new lesions per leaf that resulted after rain events. We compared the numbers of total leaves and numbers of new lesions that developed in the leaf wetness trials, to estimates for total leaves on the nearby plants that were monitored all season and the largest increases in lesions that occurred between observation times. From these calculations (data not shown), we found that providing spore-free water for 2 days resulted in two to four times as many new lesions as the most efficient rainy periods. Sufficient viable inoculum was clearly present on the leaves at the time that they were misted and bagged. Only the leaf environment needed to be altered to promote disease development.

While the provision of supplemental leaf wetness resulted in newly infected leaves and shoots, the infection rate and incidence of diseased leaves remained low. The incidence of diseased leaves on any given stem varied considerably from plant to plant (M. Newcomb, C. D. Upper, and D. I. Rouse, unpublished data). When averaged over all plants, the average incidence of diseased leaves per plant never exceeded $11 \%$ in 2007 (data not shown), the year when disease was more prevalent. Healthy leaves generally predominated, even though some plants exhibited $100 \%$ incidence of diseased leaves after times of frequent rains.

Infectious period. Jeger (11) provided theoretical arguments that the length of the infectious period can have a strong influence on the rate of disease increase under some conditions. We found that infectious rust lesions on $R$. missouriense were removed from the system during the intervals between major rain events. Moreover, we found that the leaf environment can be unfavorable for infection during long periods between rain events. Thus, simulation models that include the assumptions of constant environments and hosts, which are not met for this system, do not apply and the conclusion based on these models that the length of the infectious period has little influence on disease progress $(17,29)$ is probably not appropriate here. Because the length of time between conducive rain events sometimes exceeded the mean dura-
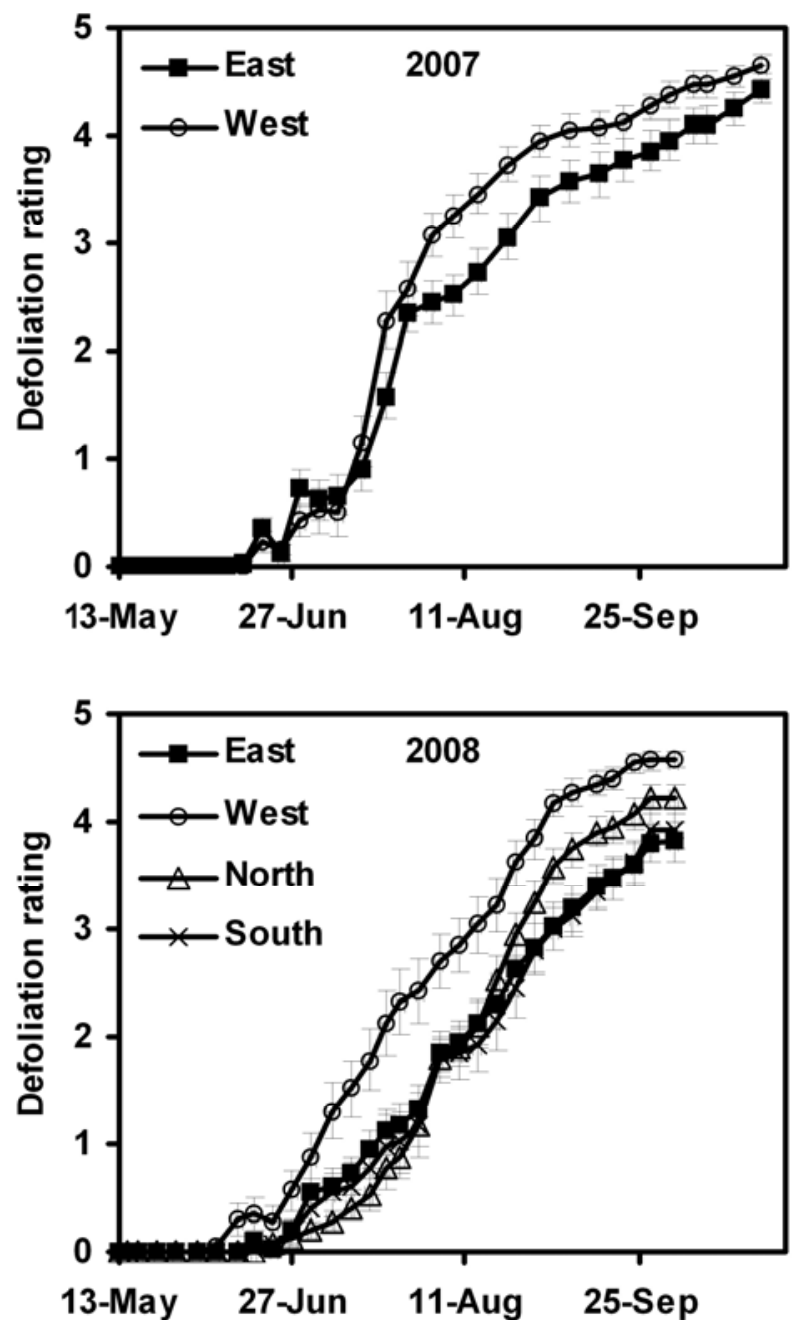

Fig. 5. Seasonal progress of defoliation of plants of Ribes missouriense at two sites in 2007 and 2008 and two additional sites in 2008. See methods for nine categories between 0 and 5. Mean ratings are shown for 30 and 31 plants at the West and East sites, respectively, and for 24 plants at each of the North and South sites. Error bars represent \pm one standard error of the mean. 

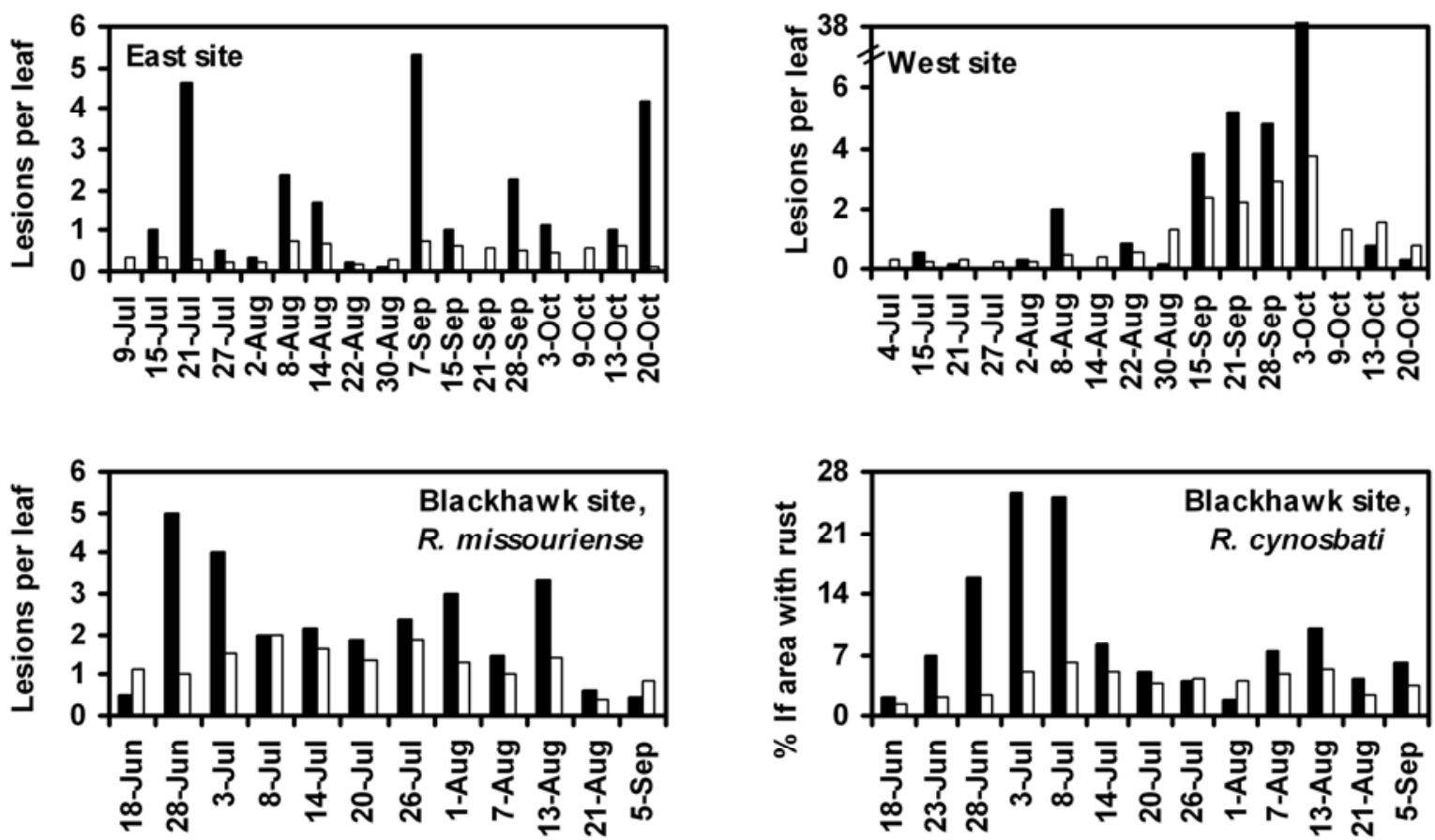

\section{Leaves that will abscise before next observation date $\quad$ Leaves that will remain attached}

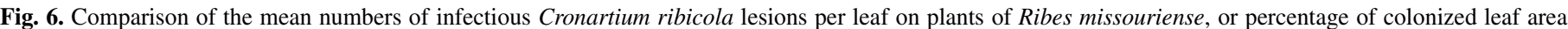

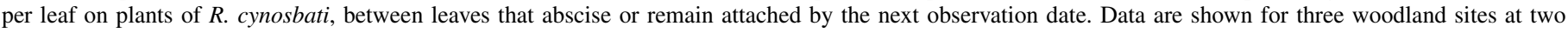
locations.

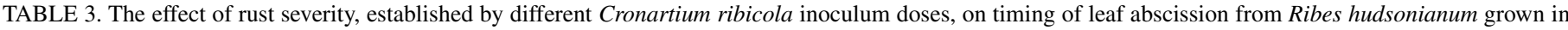
cold frames

\begin{tabular}{|c|c|c|c|c|}
\hline \multirow[b]{2}{*}{ Experiment $^{\mathrm{a}}$} & \multirow[b]{2}{*}{ Rust severity treatment ${ }^{b}$} & \multicolumn{3}{|c|}{ Days postinoculation for trial $1(\text { trial } 2)^{c}$} \\
\hline & & $13-20(12-19)$ & $21-29(20-28)$ & $30-41(29-41)$ \\
\hline Experiment 1 (fall) & Low & 0 & 15 & 36 \\
\hline \multirow[t]{3}{*}{ Trials 1 and 2} & Medium & 6 & 38 & 7 \\
\hline & High & 49 & 2 & 0 \\
\hline & & \multicolumn{3}{|c|}{ Days postinoculation for trial $1(\text { trial } 2)^{\mathrm{c}}$} \\
\hline Experiment $^{\mathrm{a}}$ & Rust severity treatment ${ }^{\mathrm{b}}$ & $27-31(25-29)$ & $32-40(30-38)$ & $>40(>38)$ \\
\hline Experiment 2 (spring) & Low & 2 & 9 & 35 \\
\hline \multirow[t]{2}{*}{ Trials 1 and 2} & Medium & 6 & 37 & 24 \\
\hline & High & 44 & 2 & 0 \\
\hline
\end{tabular}

${ }^{a}$ Data are pooled across two trials in each of two experiments (fall 2006 and spring 2007).

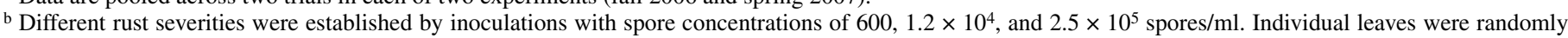
assigned to treatment groups. In experiment 2, mean percent leaf areas with rust were estimated by photographs and image analysis software as $0.9 \%$ (low), 12 to $16 \%$ (medium), and 66 to $82 \%$ (high). In experiment 1 , rust severities were estimated categorically as low (0 to $10 \%$ leaf area with rust), medium (11 to $60 \%)$, and high (greater than $60 \%$ ).

c Values shown are the numbers of leaves for each treatment group that abscised during each time interval.

tions of infectious periods (Fig. 2 and Table 2), the length of the infectious period could have substantial epidemiological importance in this disease system, and potentially for others in which the duration of nonconducive environments frequently exceeds the durations of infectious periods.

Rust severity and leaf abscission. Experiments in the woods (Fig. 6) and in a cold frame (Table 3) provide evidence that leaves with high lesion densities abscised earlier than leaves with low lesion densities. While the lesion density manipulation was conducted on a different species ( $R$. hudsonianum) than the woodland plants, inoculated leaves of woodland $R$. missouriense hosts were observed to abscise more rapidly than nearby leaves that were not inoculated during other experiments. Disease-related leaf abscission is recognized as detrimental to plant health in other systems with woody hosts, for example orange (8), cherry (37), and apple
$(27,33)$ trees, and blueberry bushes $(22)$. However, the epidemiological significance may be different for this system in which rust lesions are only infectious while host leaves remain attached, in contrast to systems involving necrotrophic pathogens or rusts with overwintering stages associated with dead host tissue. Because higher densities of $C$. ribicola lesions are associated with earlier leaf abscission, and because abscised leaves are no longer infectious, this density-dependent or self-limiting process may contribute to an upper bound on rust severity. The highest recorded percent leaf area colonized by infectious rust on any individual $R$. missouriense leaf, considering all plants and observation dates, was $25 \%$ in 2007 and $22 \%$ in 2008 . Rust-influenced leaf abscission limits spore production by removing active fruiting structures, and appears to function as a rate-reducing form of resistance for this system. 

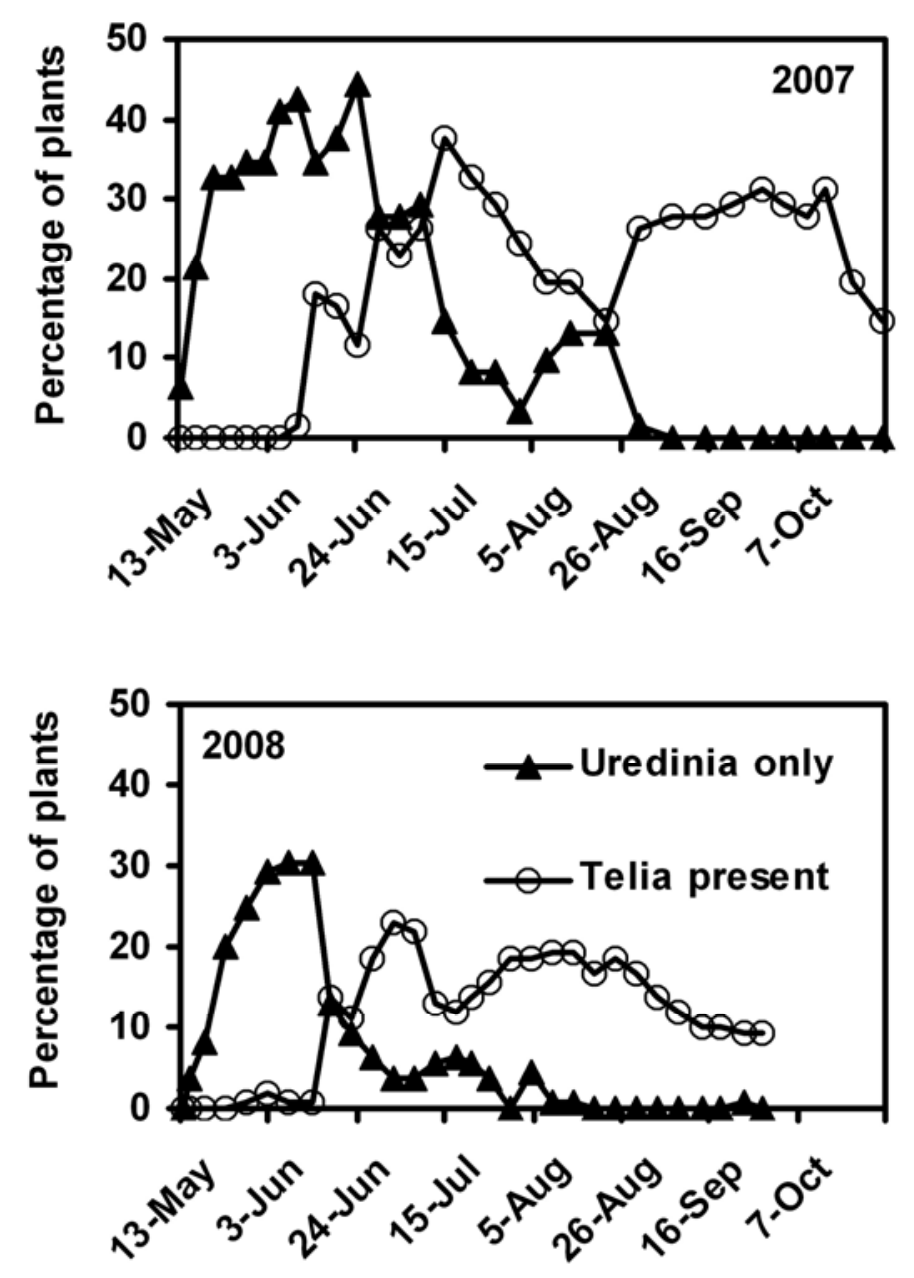

Fig. 7. Percentages of plants of Ribes missouriense with telia of Cronartium ribicola, or with uredinia only (no telia), in 2007 (East and West sites, N = 61 plants) and 2008 (East, West, North, and South sites, $\mathrm{N}=109$ plants).

Leaf abscission from some Ribes hosts has been proposed to be associated with severity of rust colonization and environment $(12,13)$. However, to our knowledge there are no previous reports that quantitatively describe patterns of leaf abscission that relate the loss of leaves to the abundance of rust, for $C$. ribicola on Ribes hosts.

Telial development. From an ecological perspective, the switch from uredinial to telial production redirects the energy of C. ribicola from producing spores capable of amplifying an epidemic on Ribes hosts to spores capable of infecting the pine host. There are obvious reproductive advantages to a spore that can reinfect the same host over multiple generations in the same season. However, there are obvious survival benefits to dispersal from Ribes to pine hosts, where cankers are perennial. Given the stochastic nature of rainfall events, coupled with the densitydependent relationship between rust severity and timing of leaf abscission, delayed telial production may be a risky strategy. The trend for telial production to occur at a low level from late May or early June throughout the remainder of the growing season, with complete conversion to telia only in the last month of the growing season (Figs. 7 and 8) suggests that the rust has adopted a strategy that allows for the persistent potential for infection of both hosts.

From an epidemiological perspective, evaluation of the importance of season-long production of telia awaits better knowledge of the season-long likelihood of success of infection of the pine host. The abundant blister rust cankers on near-by white pines inform that $C$. ribicola is successful during some years in this environment. The abundant mature white pines in the area simultaneously inform that white pines also remain successful in this
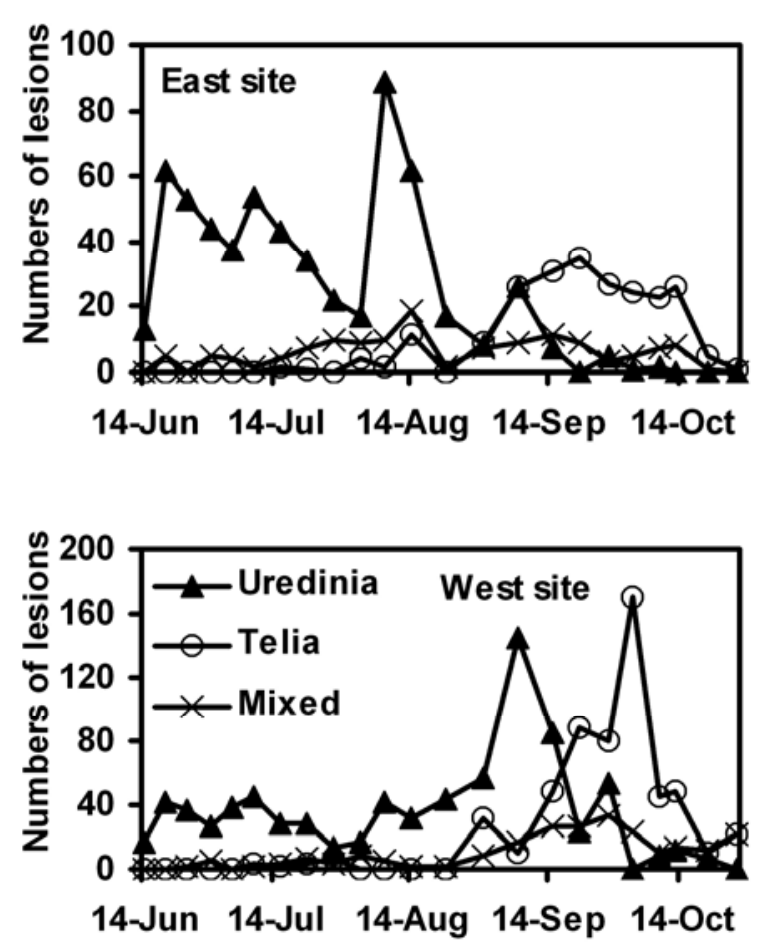

Fig. 8. Numbers of infectious lesions of Cronartium ribicola on leaves of Ribes missouriense that were tagged and repeatedly measured during the 2007 growing season at the East and West sites. Lesions are categorized by fruiting body development as those supporting uredinia only, a mixture of uredinia and telia, or telia only for all active lesions found on the 48 and 30 tagged leaves that were colonized at some time during the season on nine and eight plants at the East and West sites, respectively.

environment, despite many decades of coexistence with the introduced pathogen.

Collectively, these results advance our understanding of the epidemiology of $C$. ribicola on Ribes hosts. Further research is needed to develop a more complete quantitative model of this system that includes the interacting components of the pathogen, environment, and hosts as they vary temporally and from place to place. Such a model may prove useful for management of this destructive disease. In order to develop a more complete model, many of the knowledge gaps that need to be addressed relate to the pathogen and its Ribes hosts (31). Once we have a good model for the epidemiology of the diseases on both hosts, it may be possible to identify weak points in the system where management may effectively intervene.

\section{ACKNOWLEDGMENTS}

This research was supported by the Department of Plant Pathology, University of Wisconsin-Madison. C. Grau and J. Andrews are acknowledged for assisting with various aspects of the research. We are grateful to an anonymous person for providing input and discussions on earlier drafts of this manuscript, and two anonymous referees for their comments. We thank A. Virchow for assisting with field and greenhouse work, N. Keuler for statistical consultation, A. Huseth for map preparation, and K. Upper for providing site access.

\section{LITERATURE CITED}

1. Barnes, C. W., Kinkel, L. L., and Groth, J. V. 2005. Spatial and temporal dynamics of Puccinia andropogonis on Comandra umbellata and Andropogon gerardii in a native prairie. Can. J. Bot. 83:1159-1173.

2. Burdon, J. J., Thrall, P. H., and Ericson, L. 2006. The current and future dynamics of disease in plant communities. Annu. Rev. Phytopathol. 44:19-39.

3. Chatfield, C. 2001. Time-Series Forecasting. Chapman \& Hall/CRC, Boca Raton, FL.

4. Dalgaard, P. 2002. Introductory Statistics with R. Springer-Verlag, New York. 
5. Ericson, L., and Burdon, J. J. 2009. Linking field epidemiological and individual plant resistance patterns in the Betula pubescens-Melampsoridium betulinum host-pathogen interaction. Oikos 118:225-232.

6. Garry, G., Salas, A., Forbes, G. A., Perez, W., Santa Cruz, M., and Nelson, R. J. 2005. Host specialization not detected among isolates of the EC-1 lineage of Phytophthora infestans attacking wild and cultivated plants in Peru. Eur. J. Plant Pathol. 113:71-81.

7. Gilbert, G. S. 2002. Evolutionary ecology of plant diseases in natural ecosystems. Annu. Rev. Phytopathol. 40:13-43.

8. Hidalgo, H., Sutton, T. B., and Arauz, F. 1997. Epidemiology and control of citrus greasy spot on Valencia orange in the humid tropics of Costa Rica. Plant Dis. 81:1015-1022.

9. Hunt, R. S. 2003. White pine blister rust. Recent Res. Dev. Mycology 1:73-85.

10. Hunt, R. S., and Jensen, G. D. 2000. Long infection period for white pine blister rust in coastal British Columbia. HortTechnol. 10:530-532.

11. Jeger, M. J. 1984. Relation between rate parameters and latent and infectious periods during a plant disease epidemic. Phytopathology 74:11481152.

12. Kimmey, J. W. 1935. Susceptibility of principal Ribes of southern Oregon to white pine blister rust. J. For. 33:52-56.

13. Kimmey, J. W. 1945. The seasonal development and the defoliating effect of Cronartium ribicola on naturally infected Ribes roezli and $R$. nevadense. Phytopathology 35:406-416.

14. Kinloch, B. B. 2003. White pine blister rust in North America: Past and prognosis. Phytopathology 93:1044-1047.

15. Liebhold, A. M., Macdonald, W. L., Bergdahl, D., and Maestro, V. C. 1995. Invasion by exotic forest pests-a threat to forest ecosystems. For. Sci. 41:1-49.

16. Loo, J. A. 2009. Ecological impacts of non-indigenous invasive fungi as forest pathogens. Biol. Invasions 11:81-96.

17. Luo, Y., and Zeng, S. M. 1995. Simulation studies on epidemics of wheat stripe rust (Puccinia striiformis) on slow-rusting cultivars and analysis of effects of resistance components. Plant Pathol. 44:340-349.

18. Maloy, O. C. 1997. White pine blister rust control in North America: A case history. Annu. Rev. Phytopathol. 35:87-109.

19. Messinger, W., Hummer, K., and Liston, A. 1999. Ribes (Grossulariaceae) phylogeny as indicated by restriction-site polymorphisms of PCRamplified chloroplast DNA. Plant Syst. Evol. 217:185-195.

20. Mielke, J. L. 1943. White pine blister rust in western North America. Yale University: Yale University School of Forestry Bulletin. Report 52.

21. Montgomery, D. C., Peck, E. A., and Vining, G. G. 2001. Introduction to Linear Regression Analysis. 3rd ed. John Wiley \& Sons, New York.

22. Ojiamba, P. S., and Scherm, H. 2005. Survival analysis of time to abscission of blueberry leaves affected by Septoria leaf spot. Phytopathology 95:108-113.

23. Pariaud, B., Robert, C., Goyeau, H., and Lannou, C. 2009. Aggressiveness components and adaptation to a host cultivar in wheat leaf rust. Phytopathology 99:869-878.

24. Price, J. S., Bever, J. D., and Clay, K. 2004. Genotype, environment, and genotype by environment interactions determine quantitative resistance to leaf rust (Coleosporium asterum) in Euthamia graminifolia (Asteraceae). New Phytol. 162:729-743.

25. R Development Core Team. 2007. R: A Language and Environment for
Statistical Computing. R Foundation for Statistical Computing, Vienna, Austria.

26. Rogers, D. A., Rooney, D. P., Olson, D., and Waller, D. M. 2008. Shifts in southern Wisconsin forest canopy and understory richness, composition, and heterogeneity. Ecology 89:2482-2492.

27. Rosenberger, D. A., Engle, C. A., and Meyer, F. W. 1996. Effect of management practices and fungicides on sooty blotch and flyspeck disease and productivity of Liberty apples. Plant Dis. 80:798-803.

28. Roy, B. A. 1993. Patterns of rust infection as a function of host genetic diversity and host density in natural populations of the apomictic Crucifer, Arabis holboellii. Evolution 47:111-124.

29. Sackett, K. E., and Mundt, C. C. 2005. The effects of dispersal gradient and pathogen life cycle components on epidemic velocity in computer simulations. Phytopathology 95:992-1000.

30. Salah, A. A., Ahmed, H. U., Todd, T. C., Travers, S. E., Zeller, K. A., Leslie, J. F., and Garrett, K. A. 2010. Relatedness of Macrophomina phaseolina isolates from tallgrass prairie, maize, soybean, and sorghum. Mol. Ecol. 19:79-91.

31. Samman, S., Schwandt, J. W., and Wilson, J. L. 2003. Managing for healthy white pine ecosystems in the United States to reduce the impacts of white pine blister rust. US Dep. Agric. For. Ser. Rep. R1-03-118.

32. Schmitz, H. F., and Grant, R. H. 2009. Precipitation and dew in a soybean canopy: Spatial variations in leaf wetness and implications for Phakopsora pachyrhizi infection. Agric. For. Meteorol. 149:1621-1627.

33. Sharma, I. M., and Bhardwaj, S. S. 2003. Efficacy and economics of different fungicide spray schedules in controlling premature defoliation disease in apple. Plant Dis. Res. 18:21-24.

34. Soubeyrand, S., Held, L., Hohle, M., and Sache, I. 2008. Modelling the spread in space and time of an airborne plant disease. J. R. Statist. Soc. C, Appl. Statist. 57:253-272.

35. Spaulding, P. 1922. Viability of telia of Cronartium ribicola in early winter. Phytopathology 12:221-224.

36. Spaulding, P., and Gravatt, A. 1925. Longevity of the teliospores and accompanying uredospores of Cronartium ribicola in 1923. J. Agric. Res. 31:901-916.

37. Sztejnberg, A. 1986. Etiology and control of cherry leaf spot disease in Israel caused by Cercospora circumscissa. Plant Dis. 70:349-351.

38. Thrall, P. H., and Burdon, J. J. 2000. Effect of resistance variation in a natural plant host-pathogen metapopulation on disease dynamics. Plant Pathol. 49:767-773.

39. Tugume, A. K., Mukasa, S. B., and Valkonen, J. P. T. 2008. Natural wild hosts of sweet potato feathery mottle virus show spatial differences in virus incidence and virus-like diseases in Uganda. Phytopathology 98:640-652.

40. USDA, NRCS. 2009. The PLANTS Database. National Plant Data Center, Baton Rouge, LA. http://plants.usda.gov.

41. Van Arsdel, E. P., Riker, A. J., and Patton, R. F. 1956. The effects of temperature and moisture on the spread of white pine blister rust. Phytopathology 46:307-318.

42. Waggoner, P. E., and Aylor, D. E. 2000. Epidemiology: A science of patterns. Annu. Rev. Phytopathol. 38:71-94.

43. Wisler, G. C., and Norris, R. F. 2005. Interactions between weeds and cultivated plants as related to management of plant pathogens. Weed Sci. 53:914-917. 